\title{
A Study on Ability Structure and Training Mode of College Sports Talents
}

\author{
Maolin Tian \\ College of Sports Science \\ Jishou University \\ Jishou, 416000 China \\ 278670622@qq.com
}

\begin{abstract}
In colleges sports culture, college students are the main body, colleges and universities are the main development space of sports culture. In the quality education of college students, it is a powerful supplement to improve their personal ability, and to spread and recreate campus culture. Sports culture of the talent cultivation in colleges and universities exis ts certain difficulties in the practical teaching, and this has something to do with people's subjective factors and objective factors of teaching atmosphere, but the main factor is individual. Thus, colleges need to improve personnel training mode and improve the sports culture transmission and training strategy, so as to further perfect university interdisciplinary talents cultivation model.
\end{abstract}

Keywords-college students; sports culture; study on training model

\section{INTRODUCTION}

In 2005, the concept of sports culture existed from very ancient times. "Six Arts" of ancient Confucianism contains "shooting" and "imperial"-- two categories of sports education subjects. "Shooting" refers to the archery and "imperial" is carriages technology. This proves that the ancients in talent training system had been started to pay attention to the cultivation of sports culture and skills. The modern campus sports culture was introduced into China after the May 4th New Culture Movement, which set up a training mode to strengthen students' physique and improve their will quality. The party and our country attach great importance to contemporary campus sports culture development, and in developing education atmosphere of college quality education, physical culture education has become a important content of improving training mode.[1]

\section{The Training System of College Sports Culture on TALENT ABILITy STRUCTURE}

Although sports culture was brought by the development of modern sports new words, but in our sports culture has a long history, and philosophy, psychology, professional technical disciplines together become a part of the personnel training mode. Sports culture takes sports activities as the media. It completes the process of adjusting its own emotion

Fund Project: Funded by 2017 Hunan Education Department Scientific Research Project (17C1335)

Introduction: Maolin Tian(1976-), male, Hunan Baojing people, master's degree, lecturer, mainly engaged in sports theory and practice research and group relations by changing its outlook on life and world view. Because of the sports activity itself with the characteristics of The Times, nationality and sociality, so sports culture is also reflected The Times characteristics, era is to cultivate talents, analytical ability to structure an important tool. Sports culture is a broad concept, and media sports as medium of art, an academic, religious, entertainment, culture, class activities or sports work, can be classified as the category of sports culture, such as sports, sculpture, literature, sports study and sports communication, etc.

Therefore, the campus sports culture is a special case of the sports culture, which has a specific research space, namely the campus, which is a prominent feature of the campus sports culture, and also the basis of its stronger specificity. The cultivation of the campus sports culture with a particular object or student, and is facing students groups in colleges and universities, the sports culture is divided into two aspects, one is the classroom teaching level, namely, within the scope of the sports activities, physical education and teaching is its main activity space on campus, mainly for the sports technical skills training, such as football, basketball, volleyball, rhythmic gymnastics, such as professional sports curriculum learning, in cultivating students awareness of sports, and excavate potential in some students to engage in sports activities, to increase employment skills; another is the extracurricular teaching level, namely the extracurricular sports activities, to campus for the space, also can go beyond the campus space, usually with the political, economic, education and other social cultural activities, such as sports activities, is the student to participate in social practice is an important window, is to cultivate students will quality, unity, cooperation spirit and interpersonal skills, problem solving skills such as idea method of important practice basis.[2]

As a rich education concept, sports culture also covers rich cultural concepts. Sports culture for the cultivation of the talented person ability structure can be roughly divided into three levels: the cultivation of the ability of surface structure is based on the operational level, that is mentioned in the study of sports techniques and skills, can also be understood as the process of sports culture from abstract to 
concrete, including the specific sports study, sports and fitness habits of guidance and training, etc., see more at inclass teaching, is the student's first thought on sports and sports culture; middle the cultivation of the ability structure is based on students' understanding of the sports system and organization system, and guide students to actively participate in some sports cultural organization activities, in order to improve the students' interpersonal skills and coordination skills; deep is the cultivation of the ability structure of the sports related cultural content, including philosophy, aesthetics, sports health, as well as ideology and value judgment, etc., is based on sports to the cultivation of students' mental development. In short, the sports culture on the cultivation of the talented person ability structure of comprehensive, full-service, in sports technical skills for representational teaching content, aiming at training the ability to solve the problem, and then rise to the spiritual hierarchy and the thoughts of the ideological training, of theory with practice in college talent cultivation system.

\section{The CurRent Situation of Cultivating Sports Cultural Talents in COLleges and Universities}

At present, colleges and universities are vigorously promoting education in quality, which makes sports culture occupies an increasingly important position in talent ability structure training. Many colleges and universities have strengthened their investment in sports culture talent training.

First of all, it is based on the training of sports technology and skills. As an important education subject in university education system, physical education is guided by education for quality and carries out teaching activities in physical education programs. For example, football, basketball, volleyball and other collective sports, aimed at cultivating students' collectivism spirit and coordination ability; and confrontational sports such as table tennis, badminton, tennis, aims to cultivate the students' thinking ability and the ability to respond to, in order to develop students' problem solving thinking, cultivate their solution to the problem; in addition, individual sports such as swimming and long-distance running are designed to cultivate students' endurance and toughness, so as to enhance their basic physical quality and achieve the purpose of honing their will quality. From the point of view of sports technology and skill training, college physical education courses are the leading part, starting from cultivating students' interest in sports, so as to improve students' sports function and thinking ability. This kind of talent training mode belongs to the mass training mode, and less consideration is given to students' personal expertise. Therefore, it is mostly used in the field of curriculum teaching.

Secondly, the cultivation of social practice activities based on sports activities. Sports are a sport integrated with life, which can promote interpersonal relationship, improve personal coordination ability and cultivate people's emotional intelligence. People who are engaged in sports culture usually have a high eq. While promoting community work, colleges and universities are also strengthening the support and promotion of social activities related to sports culture. For example, campus football and basketball games are mostly organized by student groups, which is a content of the school to promote the work of student societies, and also promote the spread of sports culture through club activities. Of course, what is more important is that students have trained their interpersonal communication and coordination ability in all aspects of the organization and implementation of the competition, which is the core idea of the middle-level talent training mode in sports culture. However, this kind of talent training model has its limitations, and it is not very participatory for students who do not participate in club activities.[3]

Thirdly, training based on sports culture research. It is mainly used for the cultivation of sports philosophy, sports aesthetics, sports health and other aspects of knowledge, in order to cultivate students' ideological ideology and value judgment ability. Because of the level of training has risen to the height of the theoretical research, therefore in the process of cultivating more limitations, mainly for good professional sports and sports elective professional students, and other professional students' participation is not high. In addition, sports is a practice of sport, a lot of philosophy research work was done based on the rich practical experience, thus requiring students have many years of experience in sports, which leads to the limitations of the training mode.

All in all, sports culture as an important content of quality education position, education goal is to train compound person, from professional skills to will quality, to the interpersonal communication, coordination, and ideology, is a comprehensive and integrated training mode. Sports culture, with its unique form and concept of cultural communication, has been integrated into all aspects of college personnel training.

\section{Strategies for IMPROVIng the Training Mode OF College Sports Cultural Talents}

Education and dissemination of sports culture in colleges and universities is becoming more and more attention to sports culture will also be training mode into the day-to-day teaching and campus culture construction, but judging from the above analysis, sports culture training mode is still larger room to improve.

Firstly, the construction of sports culture should be integrated into all aspects of the talent training system, especially the content of sports culture should be strengthened in the talent training mode of non-sports majors. From strengthening sports culture in the teaching system of credits and schooling, guides the student to the attention of the sports from the ideology, attach importance to the balanced development of "intelligence and sports", 
through the intersection of knowledge, to realize sports style and professional courses, training mode more comprehensive; on the other hand, by consciously blurring the professional boundaries, students can not only pursue knowledge, but also stimulate the active power of motor nerve, and learn to maintain a vigorous mental state. Such as students in professional learning at the same time also to participate in sports activities, to break the limitations of classroom teaching, effectively extending the sports classroom, can organize sports outside school, or organize student participates in sports activities, in order to promote students' all-round development.

Secondly, the development law of sports culture and the talent training system are combined to guide students to improve their overall quality and adapt to the needs of talents in the new era. On the one hand, strengthen the physical education, and ascend to the height of political quality education, in order to attract the attention of the students, through the will quality training, causes the student to widen our sight and take an active part in sports club activities, through the sports culture to enhance students' interest to participate in social activities, to cultivate the students' sports spirit and political literacy; on the other hand to through the sports culture for the physical and mental health guidance, improve the students' professional quality, through the sports activities to cultivate the students' endurance and toughness, in particular through sports activities let students experience setbacks, the rise of the difficult experience failure ahead of time, psychological preparation ahead of time to adapt to social competition, lay a foundation for career development.

Thirdly, in the social practice activities, the sports culture color is consciously highlighted to stimulate students' interest in learning, and to cultivate students' adaptability and innovation ability. The demand for talents in the new period from the traditional skilled technical transformation to innovation, whose innovative consciousness is stronger, who can better adapt to social development, to adapt to the demanding requirements of society for talents. As a practical activity, sports culture is a good platform for students to contact the society. Especially in recent years the sports culture activities, and in many parts of the college students' group as an important branch of social sports culture development, not only has the necessity of participation in social sports cultural activities, need more play to students' innovation ability and the strain capacity, actively participate in the activities of organization and implementation, for the social activities contribute their wisdom, but also provides students with a broader social practice window, cultivate the students' social ability and strain capacity. It is in such social practice that many college students stand out and are recognized by the society in advance.

Fourth, adhere to the open talent training model; provide students with a variety of training paths, so that students balanced physical and mental development. Whether it is the mastery of sports technical skills, or the academic research of sports culture, including the knowledge research of sports philosophy, sports aesthetics and sports health, it is a part of sports culture. As the cradle of talent training, the school tries its best to tap students' personal potential, guide students to independently plan their career development path, and tell students how to choose, rather than which way to choose. Through sports culture infiltration, cultivate the students' lifelong sports ideology, also cultivate the students love sports, love sports culture, inheriting the spirit of sports culture, and comprehension from sports life philosophy and life wisdom, this is the ultimate goal of cultivating talents in colleges and universities sports culture.

\section{CONCLUSION}

Sports culture education into daily teaching system is the provisions of the United Nations educational, scientific and cultural organization, in today's campus sports culture to diversified development, the status of sports culture in the compound talents training mode more and more important. Sports culture in the aspect of students' physical and mental health has played a positive role in education, not only help students to improve the health personality, cultivate the students sports optimism, perseverance, will quality, the unity cooperation spirit, can help students to improve their interpersonal skills, develop the train of thought to solve the problem, and pioneering spirit, is indispensable to cultivate all-round talents in colleges and universities education activity, is also the embodiment of the campus culture.

\section{REFERENCES}

[1] Zhang Tianhua, Zhou Xinyao. Research on Education Belief of College Students from the Perspective of Socialist Core Values [J]. Journal of Bohai University: Philosophy and Social Science Edition, 2016, 38(6):103-106.(In Chinese)

[2] Ruan Junhua, Pei Guanxiong, Pan Lei. Reflection and Optimization Path of Education Model of College Students' Belief [J]. Journal of Zhejiang University (Humanities and Social Sciences Edition), 2016(2):86-86.(In Chinese)

[3] Zhao Huowei. Research on the Education Problem of Contemporary Chinese College Students' Belief [D]. Shandong University, 2016.(In Chinese) 